\title{
A grounded theory approach to the understanding of creativity in common spaces of universities
}

\author{
Su Wanqing and Zhao Tianyu and Zou Zhichong and Kang Jian ${ }^{\mathrm{a}}{ }^{\mathrm{a}}$ and Su Jianhua ${ }^{\mathrm{c}}$ \\ aSchool of Architecture, Harbin Institute of Technology; Key Laboratory of Cold Region Urban and Rural \\ Human;Settlement Environment Science and Technology, Ministry of Industry and Information \\ Technology, Harbin,Heilongjiang, People's Republic of China; \\ bSchool of Architecture, University of Sheffield, Sheffield, UK; \\ 'School of Art,Heilongjiang University, Harbin, Heilongjiang, People's Republic of China
}

* Corresponding author: Zou Zhichong

\begin{abstract}
:
Building a highly efficient environment for creative thinking has always been the core goal of a university's environmental research. However, previous studies show that there remains a lack of a subjective understanding of the relationship between physical space and creativity in universities. This study offers insights into the structure and factors that impact creativity in common spaces of universities. Based on grounded theory and following the principle of purposive sample using 20 participants in China, 462 initial codes and 45 axis codes were generated, and 5 categories were revealed for a subjective understanding of creativity in common spaces of universities: creative behaviour, characteristics in creative thinking, humanistic environment, physical space and individual potential. More specifically, creative behaviour is the core category of the above five factors. Characteristics in creative thinking include an internal impact factor, while humanistic environment and physical space are external impact factors. In addition, individual potential is the principal reason for differences in efficiency. Meanwhile, in universities' common spaces, the humanistic environment has a greater influence than that of physical space. Teachers and students have different space requirements. Closely combining the functions of information acquisition, meditation and academic exchange would help improve creativity efficiency. Lastly, this paper reveals structure theory and 23 keywords for creativity in common spaces of universities.
\end{abstract}

KEYWORDS:

Grounded theory; Creativity; Common space; Creative behaviour; Humanistic environment; Physical space;

2018 Interactive Learning Environments

Date Received: 15 Sep 2017 Date Accepted: 21 Sep 2018

Available online: 15 Nov 2018 


\section{Introduction}

Creativity has been identified as a core goal in modern universities. In the last 50 years, there has been an increase in the empirical study of creativity(Runco and Albert, 2010). Much work has been carried out in the field of behavioural psychology, mostly surrounding the cognitive process, cognitive rules, and the brain's mechanism of creative thinking(Arlow and Brenner, 1964; Guilford, 1950; Knoblich, Ohlsson, Haider, and Rhenius, 1999; Baddeley, 1992). In the early 20th century, research on the cognitive process has been carried out in relation to creative thinking, with some theoretical models having been set up by psychologists(Wallas, 1926; Ward, Smith, and Finke, 1992; Amabile, 1988; Chessick, 2001). One of the scholars who studied the creative thinking process was Wallas, and his The Art of Thought, published in 1926, proposed the concept of incubation in four steps for creative production theory and introduced unconsciousness into the creative thinking process for the first time. Compared with conscious thought, subconscious thought has more advantages for information integration, thus facilitating the generation of more original ideas(Dijksterhuis and Nordgren, 2006).

In 1988, Amabile proposed a component model (a five-stage process) of creativity and innovation in organizations and then improved the model with the help of other colleagues(Amabile, 1988; Amabile and Pratt, 2016). The component model is a comprehensive description of both the process of individual creativity and the process of organizational innovation as well as the ways in which the two are linked through mutual influence. Amabile showed that creativity and innovation are different parts of essentially the same process. Innovation arose from activities within an organization, and creativity was defined as the production of novel and creative ideas by an individual or a small group of individuals working together (Amabile, 1988). The focus of this model is on the creative process and the organizational environment. The environment has been proposed as a broader conceptualization of the "work environment"; moreover, one should note that this work environment is an open system and is susceptible to broader socio-cultural forces.

Some studies of the creative environment have revealed the processes of creativity in knowledge and technology(Wierzbicki and Nakamori, 2005). According to creativity investment theory(Sternberg, 2006), environmental factors, including physical, psychological, and social systems, are one of the six important sources for creativity, with other factors including intelligence, knowledge, thinking mode, personality, and motivation. Much work has been carried out on the creative environment indicating that physical space could help innovation organizations improve their efficiency and verify the broader impact of human emotions(Csikszentmihalyi, 1996; Moneta and Csikszentmihalyi, 1996; Sternberg and Davidson, 1995).The triple-helix innovation theory indicates that creative space comprises knowledge, innovation, and knowledge-based space(Leydesdoff and H. Etzkowitz, 1996; Ranga and Etzkowitz, 2010). Some studies also reveal the impact of the physical environment on innovation, taking job performance and concentration ability into consideration, and provide some direction for improving work mode and office design(Moultrie, Nilsson, Dissel, Haner, Janssen, and Van der Lugt, 2007; Myerson and Ross, 2006).

Meanwhile, research on the creative environment has promoted the development of formal and informal cooperation space, reduced individual work space, and promoted the use of collaborative technologies. Smiths (Postle, 2003) found that cognitive characteristics were surprisingly similar when high-level creative potential individuals perform non-creative or creative tasks. Non-creative tasks depend on one's memory to obtain information (Zhou and Shi, 2005).Although the recollection process is involved in both creative and non-creative tasks, creative tasks are characterized by a wider range of memory-searching activities, or with fewer amounts of restrictive information. It has been found that the production of creative thinking requires more comprehensive knowledge systems(Ward, 1994). Therefore, the difference between the creative and non-creative cognitive processes is the information chosen to complete the tasks.

The research methods related to creative thinking mainly include the biographical method, experimental method, psychological measurement method, cross-cultural research, etc.(Choi, 2004; $\mathrm{Ng}$, 2003; Simonton, 2003). These methods focus on the creative thinking process in order to identify some cognitive processing systems and obtain novel and effective solutions. One of the foremost 
scholars to study creativity and creative talent using biographical research methods was the 18thcentury psychologist Francis Galton, whoseHereditary Genius, published in 1869, showed that heredity was the cause of individual differences (Harris and Galton, 1870).Some research also reveals the working mechanism of creators in the creation process(Gruber and Wallace, 1999). Since 1995 (Gardner et al, 2001), an interesting, large-scale project related to creative talents, named Good Work, has been carried out with the support of 17 foundations. This research has been continued up until now using biographical methods. The grounded theory (GT) approach would be an appropriate method with which to explore people's perceptions of the creative thinking environment. It is widely used in the social sciences and the natural sciences, such as medicine and psychology (Glaser, 2008, 1978, 1992).

In summary, although many scholars have proposed theory models of creativity, most of them have revealed creativity from a business perspective, such as Nonaka's SECI model or Amabile's Component model. Those studies have focused on its process, organization, behaviours and outcome efficiency. However, few of them have explored the relationship of physical space to creativity, especially in common spaces of universities.

This study aims to propose the factors and a model of creativity in common spaces of universities to reveal the relationship between physical space, behaviour, and creative efficiency in universities. The focus of this paper is on the behavioural research and not on teaching. This paper is organized as follows. First, Section 2 introduces the data analysis of participants collected in interviews. In Section 3 we show five categories and explain what links them. Lastly, Section 4 discusses creative individuals, creative thinking and influence factors. The paper ends with some conclusions and further works.

\section{Methodology}

2.1. Participants and interviews Harbin Institute of Technology (HIT) is one of the C9 League universities in China, which has a population of 56,500 (estimated in 2015) including 51,000 students and 5,500 faculties. HIT is a typical comprehensive research-type university in China, including most major subjects, such as science, engineering, architecture, arts, humanity and laws. Following a principal of purposive sampling (Chen, 2006), three participants were interviewed in a pilot study and 20 participants were interviewed in the formal study. The idea behind data sampling in grounded theory is to select participants who will best contribute to the understanding of the problem and the research question (Patton, 1990).

In the pilot study, valuable information was sorted out to improve the interview content and create a formal interview outline. One consideration was that the interview outline should cover the main scope of the research questions. Initial questions in the pilot study were as follows: (1) What are the characteristics of your creative thinking? (2) When do you think creatively, and what kind of environmental factors affect you? Following the pilot study, a formal interview outline was formed.

In the formal study, 20 participants were interviewed, including 9 females and 11 males, between 22 and 60 years of age. The interviewees were from various academic levels, including 7 professors(including 4 assistant professors), 4 lecturers, 2 postdoctoral fellows, $3 \mathrm{PhD}$ students and 4 graduate students, close to the statistical value in HIT (2015 estimate). The identity and gender distribution of the interviewees are shown in Fig.1. According to Lincoln and Guba(Lincoln and Guba, 1985), the number of samples for GT should be more than 12. In this study, a total of 20 participants were selected for the formal interview, which met the requirements of "purposeful sampling" of qualitative research.

The questionnaire included the following four parts: (1) Basic information on the respondents, such as age, gender, identity and the time of the interview; (2) The overall evaluation of the university's creative environment in China; (3) People's view of creative behaviour and feelings of efficiency, such as, What types of behaviour do you exhibit when doing highly efficiency creative work?; and (4) People's view of creative thinking in relation to the environment, such as, When you're doing creative work, what kind of environmental factors affect you?'

In-depth interviews lasting 30 to 60 minutes for each participant were conducted by one interviewer and were recorded with participants' consent. Following the standard procedure of grounded theory (Ellis, Strauss, and Corbin, 1992), interview data was then transformed into 
electronic text, which was analysed and sorted using Mindjet Pro10. This software can effectively improve work efficiency and will classify the non-numerical and non-structure data (WU and HUANG, 2013).

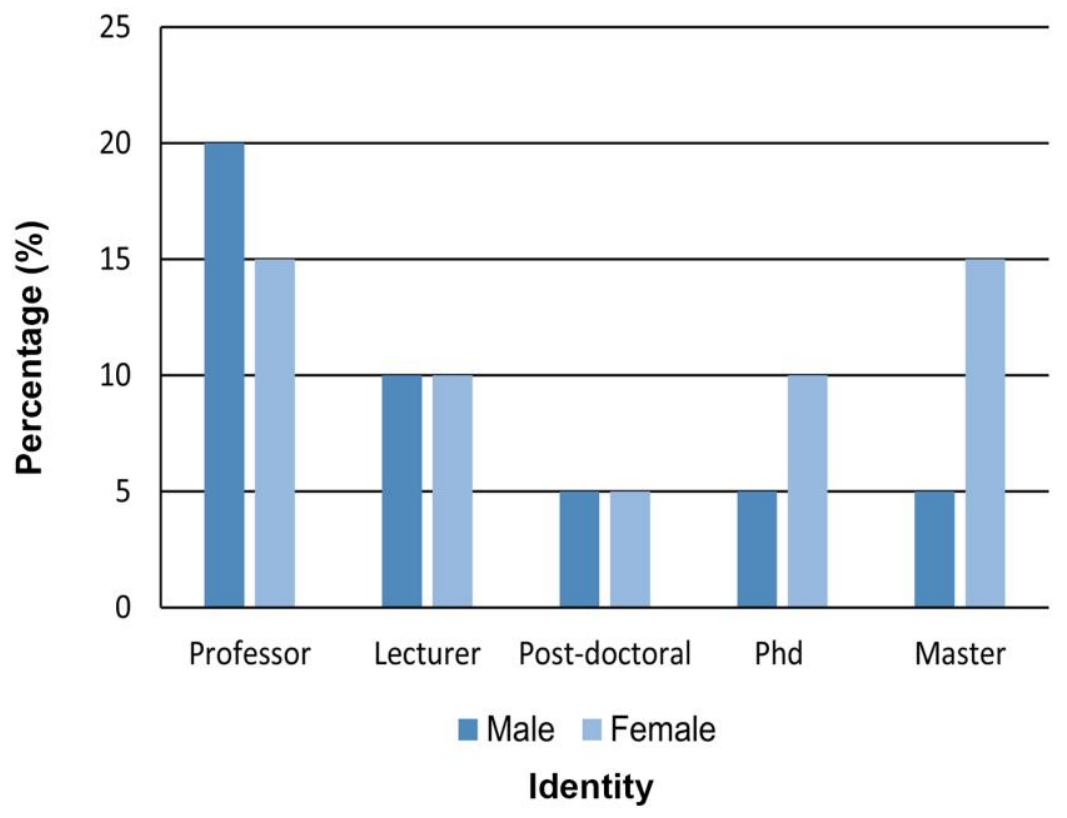

Figure 1.Analysis of respondent identities

\subsection{Data analysis}

A multi-step analysis technique based on the approaches of Glaser was employed and is shown asFig.2. The GT steps provide a clear guide to researchers (Strauss, 1987), it is as follows:

(1) Choice of the subject: purposive sampling participants who will best contribute to the understanding of the research problem.

(2) In-depth interview: Questions should be open to the purpose of stimulating thinking to find out the possible categories and properties of the material.

(3) Initial coding: emphasizing key terms in the text about the subjective understanding of creativity in common spaces of universities and coding the text;

(4) Axis coding: similar concepts were grouped together to develop categories such as creative behaviour based on some similar concepts from the responses. Other categories were formed by other grouped concepts;

(5) Theoretical coding: the core categories will be summarized, which majority of the results can be included in the theoretical scope.

(6) Linking categories: linkages were made among categories;

(7) Discovering core categories, such as a creative behaviour, which has an extensive relationship with other categories;

(8) Generating the substantive theory: concerning the subjective understanding of creativity in common spaces of universities 


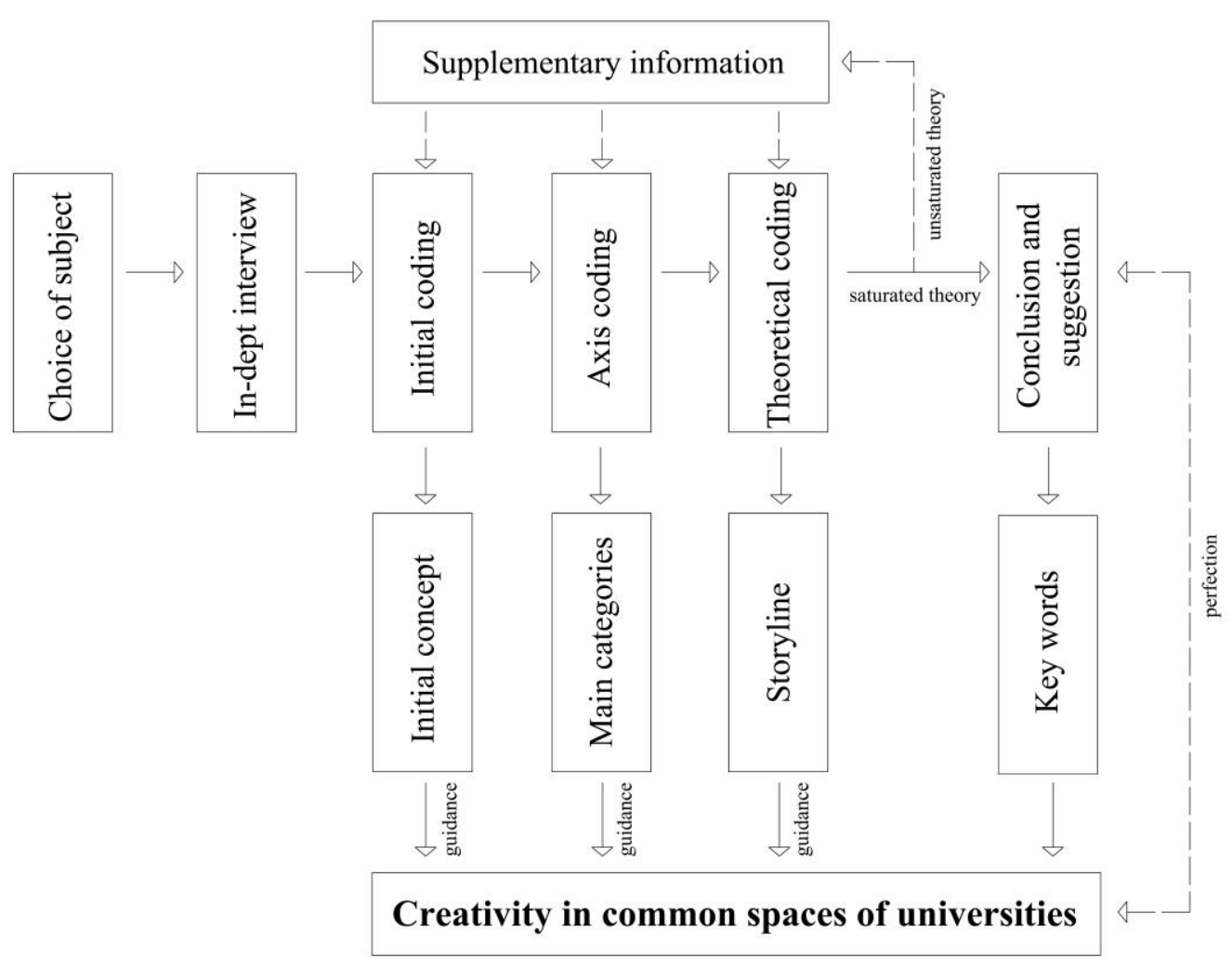

Figure 2.Step chart of Grounded Theory

In keeping with the above steps, the data were broken down into discrete ideas, events and acts. Each pheomenon was related to the public attitude towards creativity in common spaces of universities. The open coding process enabled the development of themes that were grounded in the data itself. Table 1 shows the process of initial, axial and theoretical coding based on GT, where the process involved sorting memos, labelling data, conceptualizing data and categorizing data. The initial coding is the process of breaking down, examining, comparing and conceptualizing data. The initial coding label number was 462 . To a certain extent, the concepts became clearer through open coding. Axial coding occurred concurrently with initial coding. During the data analysis step, the data were broken down into concepts and categories and then reassembled by axial coding. During the coding process, a concept was defined whenever a certain phenomenon was mentioned by two or more respondents. It can be seen that 224 initial concepts were unstructured. The next step was togather these concepts into categories based on their similarities or differences. For example, in the process of conceptualizing data, concepts aa 1 , aa 7 and aa8 were gathered into category A1. Therefore, 45 categorized items were generated. When coding axially, the object was to determine how categories link and crosscut. Once fairly developed categories emerged, selective coding began. Central to the procedure of theoretical coding was the selection of a core category and of major categories related to it and to one another. 
Table 1Coding process for open coding, axial coding, and selective coding based on GT.

\begin{tabular}{|c|c|c|c|c|c|}
\hline Sorting Memos & Labeling & Conceptualizing Data & Categorizing Data & Categories & Sub-categorized \\
\hline $\begin{array}{l}\text { (what are the characteristics } \\
\text { of your creative thinking?) } \\
\text { First, I'll search much } \\
\text { information from internet } \\
\text { and books.I like reading for } \\
\text { a long time in an } \\
\text { undisturbed environment, } \\
\text { which is also accompanied } \\
\text { by logical analysis. At the } \\
\text { same time, I often need to } \\
\text { listen to someone for } \\
\text { suggestion if I meet a } \\
\text { problem. } \\
\text { (.... } \\
\text { (When you are in creative } \\
\text { thinking, which } \\
\text { environmental factors will } \\
\text { affect you? ) } \\
\text { The environment of } \\
\text { university campuses is } \\
\text { especially important for } \\
\text { innovation.I need a very } \\
\text { quiet environment, let } \\
\text { myself to calm down and } \\
\text { immersion } \\
\text { reading.Meanwhile, I like to } \\
\text { read the literature } \\
\text { intensively in a short time } \\
\text { because it's easy to forget. }\end{array}$ & $\begin{array}{l}\text { a1 I need an environment } \\
\text { where can search } \\
\text { information from the } \\
\text { internet. } \\
\text { a2 The process of } \\
\text { immersion reading is } \\
\text { accompanied by logical } \\
\text { analysis. } \\
\text { a3 Reading the literature } \\
\text { concentrated in a short time, } \\
\text { it's easy to forget. } \\
\text { a4 I urgent need to } \\
\text { communicate with others in } \\
\text { the absence of research } \\
\text { direction. } \\
\text { a5 Thinking alone is no } \\
\text { faster than communicating } \\
\text { with others. } \\
\text { a6 Different environment } \\
\text { context produces different } \\
\text { outcomes. } \\
\text { a7 In a good environment, I } \\
\text { will feel calm down, the } \\
\text { ideas are easier to } \\
\text { concentrate. } \\
\text {..... }\end{array}$ & $\begin{array}{l}\text { aa1 The Internet is a high } \\
\text { efficient way of data } \\
\text { collection. (a1) } \\
\text { aa2 Immersion reading is } \\
\text { accompanied by depth } \\
\text { analysis. (a2, a92) } \\
\text { aa3 Concentrated reading is } \\
\text { easy to remember.(a3) } \\
\text { aa4 Urgent need to } \\
\text { communicate with others. } \\
\text { (a4,a18) } \\
\text { aa5 Different environment } \\
\text { context produce different } \\
\text { outcomes (a6, a8 and } \\
\text { a25) } \\
\text { aa6 Good environment will } \\
\text { output high efficiency. (a7) } \\
\text { aa7 Immersion thinking will } \\
\text { get inspiration. (a9,a16,a90 } \\
\text { and a118) } \\
\text { aa8 A lot of reading } \\
\text { literature helps to produce } \\
\text { innovative results. (a10,a38 } \\
\text { and a40) } \\
\text { aa9 Academic exchanges } \\
\text { can correct erroneous ideas. } \\
\text { (a11 and a52) } \\
\text { …..... }\end{array}$ & $\begin{array}{l}\text { A1Efficient information } \\
\text { acquisition (aa1, aa7and } \\
\text { aa8) } \\
\text { A2 Meditation thinking } \\
\text { environment. (aa2 and aa3) } \\
\text { A3 Academic exchange is an } \\
\text { important part of knowledge } \\
\text { innovation. (aa4, aa9 and } \\
\text { aa10) } \\
\text { A4 Different environment } \\
\text { context produce different } \\
\text { outcomes. (aa5 and aa6) } \\
\text { A5 Knowledge export is } \\
\text { important for innovation. } \\
\text { (aa11) } \\
\text { A6 Appropriate surrounding } \\
\text { pressure can improve the } \\
\text { efficiency of innovative } \\
\text { thinking. (aa12 and aa13) } \\
\text { A7 Spatial administrative is } \\
\text { an important element in } \\
\text { people's choice of innovative } \\
\text { environment (aa14, aa15 and } \\
\text { aa16) }\end{array}$ & $\begin{array}{l}\text { AA1 } \\
\text { Creative behaviour } \\
\text { AA2 } \\
\text { Creative thinking } \\
\text { characteristics } \\
\text { AA3 } \\
\text { Humanity atmosphere } \\
\text { AA4 } \\
\text { Physical space } \\
\text { AA5 } \\
\text { Individual potential }\end{array}$ & $\begin{array}{l}\text { AA1 Creative behaviour } \\
\text { Resources acquisition } \\
\text { Immersion thinking } \\
\text { Academic exchange } \\
\text { Externalization } \\
\text { AA2 Characteristics in creative } \\
\text { thinking } \\
\text { New information } \\
\text { Step forward } \\
\text { Deep thinking } \\
\text { Continuity } \\
\text { Recall difficulty } \\
\text { Fatigue easily } \\
\text { Inspiration } \\
\text { AA3 Humanistic environment } \\
\text { Social pressure } \\
\text { Organization atmosphere } \\
\text { Disturbance } \\
\text { Sense of Belonging } \\
\text { AA4Physical space } \\
\text { Functionality } \\
\text { Space quality } \\
\text { Space scale } \\
\text { Controllability } \\
\text { AA5Individual potential } \\
\text { Physiological ability } \\
\text { Creative skill } \\
\text { Intrinsic motivation } \\
\text { Task pre-judgement }\end{array}$ \\
\hline Initialdata collection & 462 items & 224 items & 45 items & 5 items & $\begin{array}{l}\text { Generating the substantive } \\
\text { theory }\end{array}$ \\
\hline
\end{tabular}




\section{Results}

Through above procedure, five main categories were generated, as shown in Fig.3. Creative behaviour (AA1) was the core category, and other major categories including characteristics in creative thinking (AA2), humanistic environment (AA3), physical space (AA4) and individual potential (AA5). Details of the linkages among categories are presented in the latter part of this section. Ultimately, the properties and characteristics of the subcategories along a dimensional range were identified.

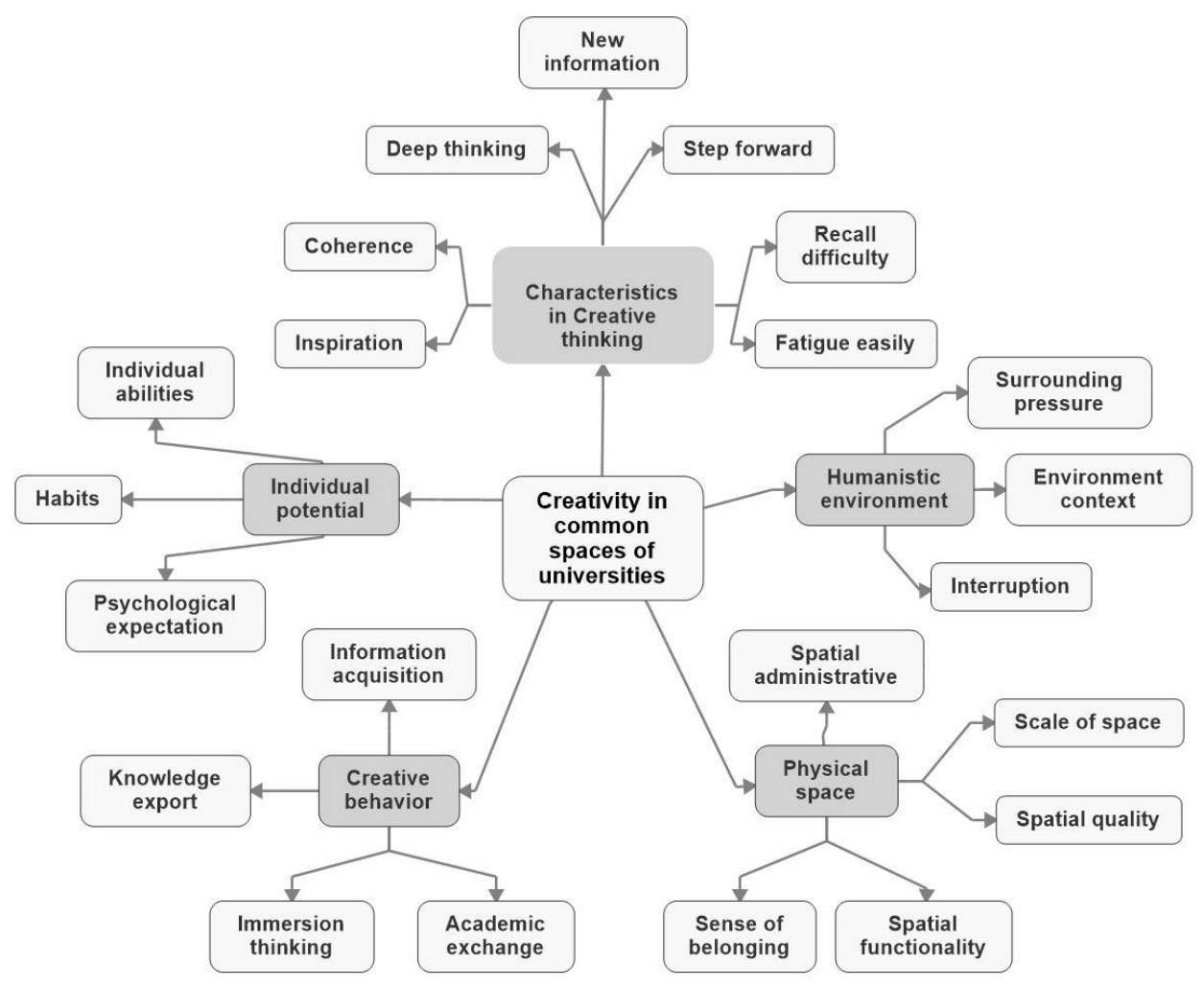

Figure 3. Structure of five core categories and twenty-two key words

\subsection{Creative behaviour}

The characteristics of the creative behaviour category are supported by 4 subcategories: "resources acquisition", "immersion thinking", "academic exchange" and "externalization".

Resources acquisition is the beginning of creative thinking and will directly affect creative thinking efficiency. There are various forms of resource acquisition, taking a class, reading and searching online, etc. The "new information" combines with the old information in one's brain and after deep analysis and integration becomes new knowledge. Therefore, it is very important for creative thinking to provide resources more conveniently. As shown in recording (A1),"In writing papers, I need a network space that is very important to me."

Immersion thinking is not only an important process of thinking from a simple to a deeper level but also a process of understanding and knowledge reprocessing. People often need independent immersion thinking; afterwards, one can be inspired, as shown in recording (A3):"Immersion reading is a process of deep analysis; it will produce inspiration gradually."

This study has illustrated that academic exchange is very helpful for the emergence of creative ideas, as it promotes the sharing and transmission of information among members of an organization. It is also assists in guiding one's research direction, correcting information, and arranging and relieving mental stress. In terms of guiding one's research direction, according to student (A4), 
"When I have no research direction, communication will be badly needed, preferably with the domain expert, which could make me progress quickly."As for correcting wrong ideas, as shown in recording (A5), "Pure deep thinking is no better than communication. That is a good way to correct wrong ideas."Academic exchange is also a process of self-promotion: the more it is debated, the clearer it becomes. At the same time, it also relieves mental tension. As demonstrated in recording (A6), "Deep thinking always makes me feel nervous, but talking with others helps reduce my tension."Academic exchange is characterized by both urgency and gradualness. People often have an urgent requirement to communicate with someone when faced with an uncertain question. However, not all academic exchanges begin with a formal academic topic. It has been found that academic exchange often evolves from an informal chat. As conversation deepens, thinking also gradually deepens. As shown in recording (A7), "Much of my research has been inspired by casual chats in a coffee shop or lounges, where conversations begin with an easy topic and gradually deepen over a long period of time."

Externalization is the process of transforming an individual' stacit knowledge into explicit knowledge (Su, 2013). New knowledge must be recorded and effectively communicated before it can be acquired by others. Various forms can be seen as knowledge output, such as writing papers, composing reports, launching a product, etc. As shown in recording (A8), "I would like to share my latest research results, such as by writing papers and making a presentation in academic meetings."

\subsection{Characteristics of creative thinking}

The characteristics of the creative thinking category are supported by 7 subcategories: "new information", "step forward", "deep thinking", "continuity", "recall difficulty", "fatigues easily" and "inspiration".

New ideas stemming from creative thinking are not generated from mere repetition but by reprocessing existing fragmented information; thus, it has the characteristics of new information, which is often referred to as "inspiration". First, inspiration can be stimulated. As shown in recording (A13), "One thing or one sentence can promote inspiration". Second, new information is easily forgotten. New information must be repeated many times to form an effective memory determined by the memory mechanism of the human brain. Therefore, continuity is very important for creative thinking, especially not being suddenly interrupted. As shown in recording (A15), one assistant professor said, "Sudden interruptions will destroy my deep thinking process, which is often difficult to recall". At the same time, in creative thinking, the mind should remain in a state of continuity for a long time. As shown in recording (A16), one professor said, "When doing efficient creative work,3 times 8 hours is better than 8 times 3 hours".

It has been found that thinking activities are hierarchical and that creative thinking belongs to deep thinking. According to one respondent (A17), "Creative work is different from other work; it is deep thinking. I need a higher environmental requirement". Usually, before achieving deep thought, a warm-up process will be needed. However, if the level of difficulty of the work is merely simple or medium difficulty, a warm-up process will not be necessary. As demonstrated in recording (A18), "Usually, if the work ahead is very difficult, I need a warm-up process before doing it, especially in the case of two difficult tasks that are hard to switch between during the same period." It usually takes a long time to let the mind go from shallow to deep thinking. It will consume much energy and easily exhaust the innovator. According to one PhD student (A19), "Creative work requires me to concentrate intensely, and it is easy for me to feel tired, so after doing 3-4 hours of creative work, I will need a rest".

\subsection{Humanistic environment}

The characteristics of the humanistic atmosphere category are supported by 4 subcategories:"organization atmosphere", "social pressure", "disturbance" and sense of belonging".

This study has illustrated that the organization atmosphere will impact an individual's creative behaviour. A nice, friendly atmosphere can promote creativity, and vice versa. According to one 
respondent (A24), “A different organization atmosphere will produce different outputs. In a good atmosphere, I feel calm, and my mind easily concentrates. However, a poor organization atmosphere will force me to leave the space, so it is difficult to do creative work."

Appropriate social pressures can improve the efficiency of creative thinking, as individuals are always more quick-witted in an emergency. According to one graduate student (A25), "During a normal period, I need 1 hour to reach the deep-thinking stage, and I have a rest after each 3-4 hours of work. However, in an emergency, one only needs 5 minutes to reach that deep-thinking stage, and one can continue working for over 10 hours."

Meanwhile, social pressures could stimulate individual motivation towards creativity. As shown in recording (A27), "Sometimes I do not want to write a paper or do any creative work, but when I notice that my partner published a high impact factor article, this will motivate me a great deal and encourage me to work."

Disturbances can greatly reduce the efficiency of creative thinking, especially unplanned emergencies such as sudden phone calls, or a temporary visitor's work arrangements. These kinds of disturbances, whether at the initial stage or the deep-thinking stage, have a great influence on creative activity. As deep thinking requires a warm-up process, sudden interruptions will delay the further development of deep thinking and even cause ideas or inspiration to vanish. As a professor working at both UK and Chinese universities said (A28), "In my office in England, it is easier for me to concentrate, but when I'm in my office in China, where there is more temporary and high-frequency work, it is difficult to think continuously, so my creativity efficiency is very low."

The sense of belonging was mentioned many times in the recordings. People feel more relaxed and able to concentrate in a space where they have a strong sense of belonging. A familiar and stable environment will help people effectively transition into creative thinking. As a professor working at both UK and Chinese universities said (A29), "In my UK office, I always work late, until 9-10pm, but in China, I would like to go home just after $6 \mathrm{pm}$. That is because my sense of belonging when in my office in China is not strong enough, and so I do not want to stay longer." According to one student (A30). "In our classroom, when there are some familiar partners around, I feel more stable and will do creative work."

\subsection{Physical space}

The characteristics of the physical space category are supported by 4 subcategories:"space quality", "space scale", "functionality" and "controllability".

The results of this study indicate that space quality, such as acoustics, light, thermal condition and odors, can affect people's creative efficiency. The comfort and satisfaction of one's space will directly affect a person's staying time and feeling of concentration, which in turn will directly affect creative efficiency. As evidenced in recording (A32), "When thinking deeply or writing a paper, I like to choose a bright, quiet room with no bad smell, which otherwise will affect my deep thinking."Space scale and furniture size can also affect people's staying time and creative efficiency, as shown in recording (A34): "I prefer a small room, and the seat should be comfortable; otherwise it is difficult to stay there for a long time."

Controllability is proposed to evaluate a user's control over the level of space quality, degree of disturbance, partner's behaviour, etc. Creative work requires a space in which the acoustics, temperature and light source can be controlled. As shown in recording (A36), "If I feel that my room temperature is hot, I can open the window for a while and the temperature will soon decrease, which will let me stay longer. Meanwhile, I do not like writing in a public library because if it closes, even if my inspiration is emerging, I must leave, so I have no control over my time."

\subsection{Individual potential}

The characteristics of the individual character category are supported by 4 subcategories: "physiological ability", "creative skill", "intrinsic motivation" and "task prejudgement".

Individuals have different physiological abilities related to creativity, such as attention, memory 
and anti-interference, and these will directly affect the depth and efficiency of their creative thinking. As shown in recordings (A39) and (A40), one respondent said, "I can be easily disturbed by noise, such as a door closing, footsteps and conversations, so it is difficult for me to concentrate for a long time."

Creative skill will affect an individual's creative efficiency, such as selecting a secluded and comfortable room and adjusting one's biological clock to adapt to a long period of creative work at night. This depends on the individual's creative experience, and it will affect his or her creative behaviour. One respondent (A42) said, "I like to meditate at midnight, when it is quiet and I am not disturbed. This helps me perform highly efficient creative work."

Intrinsic motivation is an important factor for an individual's creative efficiency. People with a high intrinsic motivation for creativity always withstand the more adverse environment and are not easily affected by external factors. One respondent (A44) said, "I am eager to solve this scientific problem, so I work day and night, and it is harder when disturbed by traffic noise". Task prejudgement would determine an individual's creative work behaviour choice. If there is little time, an individual will choose to do a simple task instead of deep thinking or creative work.

\subsection{Links among the categories}

In the structure of these five categories, creative behaviour is the core category of them, with the internal factors affecting by characteristics of creative thinking. The humanistic environment and the physical space are the external factors affecting to it, and the individual potential is the principal reason for efficiency, as shown in Fig. 4.

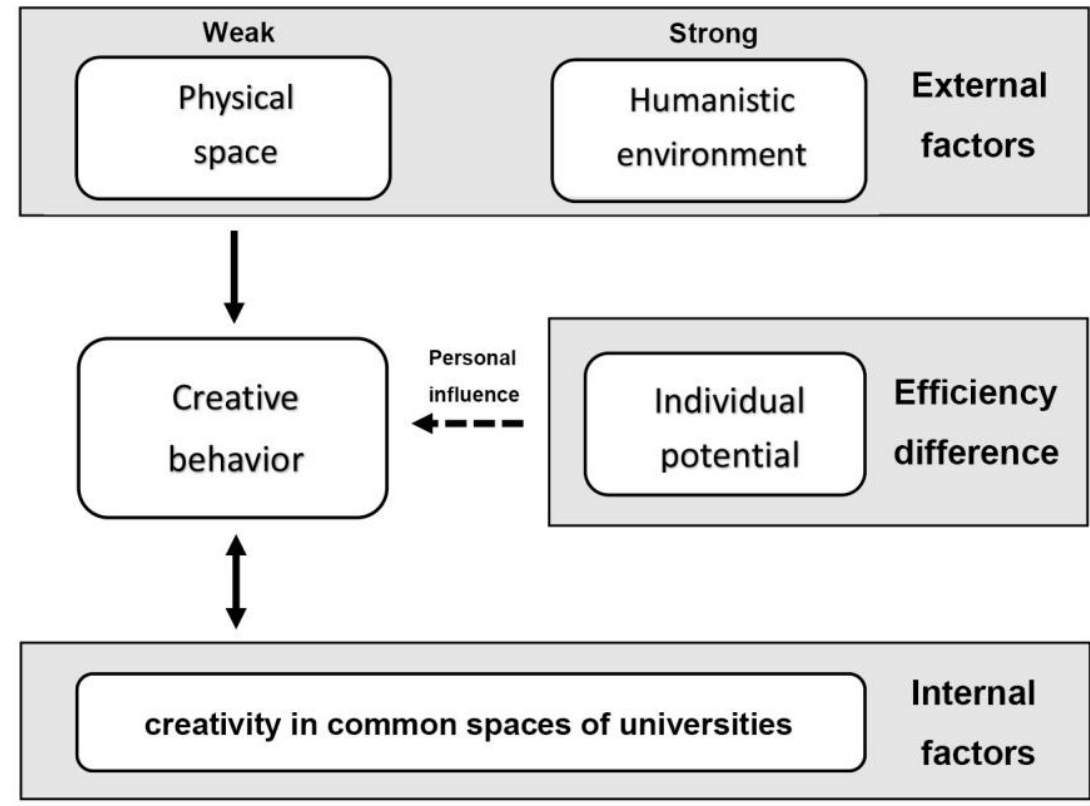

Figure 4. Links among five core categories

\subsubsection{Creative behaviour is the core category}

(1)Creative behaviour has hierarchical characteristics. The most interesting finding was that creative behaviour can be divided into three levels that deepen gradually and are indispensable. The initial level is acquiring and memorizing. As shown in recording (A12), "Reading and literature review are simple repetitions of memory and their environmental requirements are relatively low; they can be carried out on many occasions.'The middle level is understanding and correcting. As demonstrated in recording (A9), "New knowledge must be implicated many times to reach a deep understanding, and only then can it be my knowledge.'The highest level is deep rethinking. As shown in recording (A14), "Knowledge innovation is a deep rethinking of new and old materials. Only when information has been accumulated to a certain extent can 
an epiphany emerge."

(2)Creative behaviour and creative thinking characteristics are necessary and sufficient conditions for each other. First, if it fails to conform to the characteristics of creative thinking, creative behaviour will not occur. According to one lecturer (A45), "When I work in a public office, I am often suddenly disturbed and unable to think deeply, so I can do no creative work there." At the same time, if creative behaviour has occurred, it must already have met the requirements of creative thinking characteristics. According to one student (A43), "During my PhD years, I had a particularly high and efficient creative output, mainly because I was rarely disturbed by trifles and could immerse myself in work for a long time."

(3) A humanistic environment and physical space are necessary yet inadequate conditions for creative behaviour. Good atmosphere and physical space can improve the efficiency of creative behaviour, but high-efficiency creative behaviour does not necessarily require a highquality environment. According to one student (A41), "I require a higher-quality environment when my research skills are weak. However, if were better, the environment would have less of an impact on me."

\subsubsection{Humanistic environment and physical space influence creativity}

(1) A humanistic atmosphere is more influential. Compared with physical space, a humanistic environment has more of an influence on creative thinking. In a relaxed environment, it is easier to open one's mind and talk with each other and meditate. On the other hand, in a stressful and unfriendly environment, this will reduce the efficiency of creative thinking. As shown in recording (A31), "In the past, the quality of my work space was low, but since I enjoyed a good rapport with my colleagues, my creative efficiency was much higher then. On the other hand, my work space quality is better now, but my relationship with colleagues is not harmonious, so my creative efficiency is lower."

(2) Physical space requirements for teachers and students. This paper makes a comparison between teachers' data and students' data, and analyses the requirements of physical space between them, as shown in Fig. 5.We find that teachers usually gather information extensively, prefer to share their creative ideas with individuals of different backgrounds, and develop their thinking range through academic exchange. As teachers have better creative work skills, they also transition faster into immersion thinking and have higher efficiency creative outputs. Previous research reveals that creative thinking occurs when attention is not focused on a narrow range (Katz, 1983; Martindale and Hasenfus, 1978; Martindale, Hines, Mitchell, and Covello, 1984), and that low-level creative individuals tend to focus on a narrow range of thinking.

It has been shown that teachers prefer working in an independent and controllable small room, while students prefer working with others, in particular with people with similar backgrounds and identities. A comfortable environment is much needed by both teachers and students. Although some people like working in the morning, others prefer working at night, and they need a controllable space, as they are looking for a space where their deep thinking will not be interrupted. 


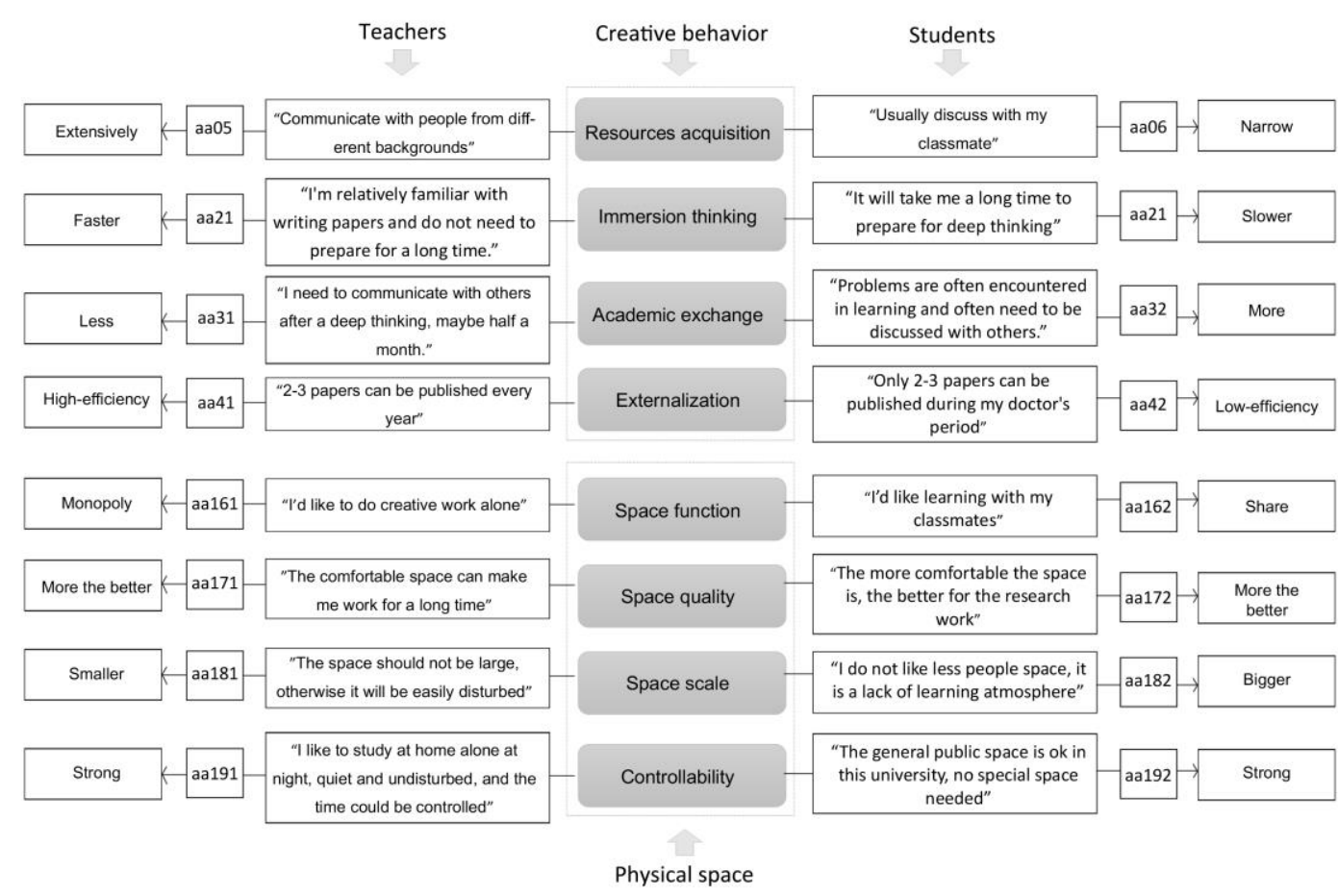

Figure 5.Diagram of different requirements for teachers and students

\subsubsection{Consistency and reliability test of results.}

As we used grounded theory methodology, the results should be auditable. Auditability refers to the ability of another researcher to follow the methods and conclusions of the original researcher. One criterion of auditability(Guba and Lincoln, 1981) is that it reflects the consistency of the research study. Auditability is demonstrated when another researcher is able to follow the audit or decision trail of all the decisions made by a researcher at every stage of data analysis(Beck, 1993). After receiving feedback from 3 associate professors and 2 doctoral students(not included in the 20 participants), this study returned to the original data many times and tested and revised its coding and further research conclusions until no new category was found, making sure the results passed through an inquiry process.

This study also attempts to conduct a reliability assessment. Our research adopts an index of code agreement, which is presented as the percentage of the number of the same codes to the total number of codes from different researchers based on the same materials: $\mathrm{CA}=2 \times \mathrm{T} 1 \cap \mathrm{T} 2 / \mathrm{T} 1 \cup \mathrm{T} 2$. $\mathrm{T} 1$ is the number of coder $1 ; \mathrm{T} 2$ is the number of coder 2 . The author created a code reference handbook of creative common spaces. In addition, the author invited two graduated students with experience in grounded theory studies (they are not on this research team but have coding experience) to code $100 \%$ and $20 \%$ of the text materials (corresponding to 20 and 5 participants, respectively) by using the code reference handbook(Guiller, Durndell, \& Ross, 2008). T11 and T21 is the total number of codes from 20materials by the author and graduated student 1 . T12 and T22 is the total number of codes from 20 materials by the author and graduated student 2 . The results were as follows: $\mathrm{T} 11=462, \mathrm{~T} 21=$ $409, \mathrm{CA} 1=0.83 ; \mathrm{T} 12=98, \mathrm{~T} 22=81$, and CA2 $=0.72$. This means that the index of the code reliability is reasonable.

\section{Discussion}

\subsection{Periodicity and gradualness in creative thinking}

This study has found that creative thinking has characteristics of periodicity and gradualness. 
Creative thinking requires a process of information acquisition, immersion thinking, inspiration emergence and knowledge output. At the same time, creative thinking is a gradual process, which goes from shallow to deep. In previous studies, Wallas's four stages of the creative process (Wallas, 1926) show that creative activities include four stages: preparation, incubation, illumination and verification. Each stage has its own content and objectives. It has been shown that creative activities are the combined effect of conscious and subconscious thought rather than a one-sided emphasis on one kind of thinking (Lubart, Kurtzberg, and Amabile, 2010). This study also reveals the important influence of the subconscious and of inspiration on creative thinking.

(1) Information acquisition and academic exchange. Information acquisition is the preparation stage of creative activity. In the initial, creative tasks for high-level creative individuals, a large amount of information was required, and irrelevant information is rejected in the following memory screening. In Amabile's componential model (Amabile and Pratt, 2016), the basic resources or raw materials at the organizational level are resources in the task domain, which includes everything the organization has available to assist creative work in a targeted area. Meanwhile, open communication systems are very helpful in facilitating idea exchange, coordination, and collaboration, and frequent, constructive, and supportive feedback on creative efforts.

(2)Immersion thinking and inspiration emergence. This study detects evidence that before a problem is solved, creative individuals tended to immerse themselves in the thinking process for a long time, which is similar to the incubation period of the four-stage theory. During this period, individuals are no longer consciously thinking, but rather are thinking subconsciously (Martindale et al, 1984).Cognitive individuals no longer consciously think about the problem and turn to do something else; however, they actually mobilize the subconscious to continue thinking. According to one assistant professor (A21), "Sometimes the problem cannot be solved immediately, I will stop it and turn to something else, but the subconscious will still help me and I will keep thinking."

It is interesting to note that inspiration is a characteristic of creative behaviour. One respondent said (A22), "When I have an unsolved problem, an occasional conversation or an article review may suddenly give me the inspiration to solve it." The four-stage theory suggests that inspiration is not a temporary, incidental gain, but the result of careful preparation and long gestation (Ritter, van Baaren, and Dijksterhuis, 2012). Dietrichhas also found that suddenness is an important feature of creative thinking (Dietrich, 2004).

\subsection{External influence for creativity}

It has been shown that the humanistic environment and the physical space are external factors for creativity and could affect an individual's creative efficiency. Many studies have indicated that social atmosphere will affect an individual's creative motivation level. Physical space, such as length of stay or frequency of communication, also affects creative behaviour.

(1) Humanistic environment. The organizational atmosphere and team members' ability will have an impact on an individual's creative efficiency. The SECI model suggests that knowledge innovation requires a mutual transformation between tacit knowledge and explicit knowledge among members of an organization. The spiral of knowledge requires a specific "Ba" (Nonaka, 1991), such as cognitive or physical space. The four stages of knowledge transformation correspond to four different types of Ba. They are "Originating Ba", "Interacting Ba", "Cyber Ba" and "Exercising Ba". The dynamic componential model reveals that three organizational components constitute the "work environment" that influences an individual's creativity (Amabile, 2016). This work environment includes all three components and shows that it is an open system subject to social, economic, cultural and other influences outside of the organization (Drazin et al.,1999 and Woodman et al, 1993).

This study reveals that the organizational atmosphere will place social pressure on creative individuals. This pressure can be divided into two kinds: explicit pressure and tacit pressure. 
Explicit pressure has a direct impact on creative individuals, while tacit pressure indirectly contributes to their creativity. In general, explicit pressure comes from a certain person or matter and has a definite function subject and definite task. According to one student (A26), "When my tutor asks me for my research report tomorrow, I will immediately feel deeply stressed." Tacit pressure originates from an individual's perception of the surrounding atmosphere; there is no definite subject or task, as it is generated by the organizational atmosphere. As shown in recording (A33), "Everyone in the library is studying, and that atmosphere makes me feel stressed, so I cannot use my mobile phone there."

(2) Physical space. In some universities, each function of space is usually designed to be independent, with the purpose to reduce disturbances between them. As demonstrated in recording A23, "If two students are always whispering near me in the library, it will annoy and disturb me very much." However, this phenomenon also indicates that both silence and communication are needed in a library space. Thus connecting the different needs of creative behaviour and making mixed use of a surrounding space are also very important factors. However, the space function must be both independent and mixed-use. Independence aims to reduce disturbance, and mixed use aims to combine the functions of information acquisition, deep thinking, academic exchange and attention restoration. When inspiration occurs, people often have an urgent need to communicate with others, so deep thinking and academic exchange spaces should be adjacent to each other. At the same time, network using and attention restoration will also influence the space choice of creative individuals.

High-intensity creative work is exhausting, and an uncontrollable environment will increase people's sense of fatigue; even if it is only the psychological expectation of disturbance, the fatigue will still increase. As shown in recording (A20), "My work time is similar in both China and the UK, but the feeling of fatigue is different. In China, I always worry about something temporary happening suddenly, which makes me feel more tired and lessens my creative efficiency."

\subsection{Physsical space and creative behaviour}

The physical space layout mode of different functions has a certain influence on the efficiency of people's creative behaviour. Usually, people focus on their "core" functions in campus space design and ignore the "systemic" nature of the creative behaviour. For example, people often think that the library is the best place for immersion thinking on campus. Therefore, in order to meet the core function of "quietness" and reduce noise interference, it is usually "no conversation" in the library. However, timely and effective communication is one of the important processes to improve the efficiency of creativity, but it is not valued by designers and managers, so it is often not satisfied in the physical space setting.

This study shows that physical space can affect people's comfort, staying time, etc., thus affecting the efficiency of people's creative behaviour. According to the characteristics of creative thinking and creative behaviour, a highly attractive mix-used space should be created on campus instead of focusing on a functional partition. It must be able to meet the needs of immersion thinking and learning, but also to provide resources acquisition, immersion thinking, and academic exchange. For example, in the library, in addition to immersion thinking space, more space is needed, and the silence rooms should be adjacent to the leisure space or common space. In the design of office space, large and medium-sized integrated offices should be minimized, and space should be divided into multiple small and relatively independent offices, thereby increasing people's controllability of space and setting up an exchange area nearby. This will enable resources acquisition, immersion thinking, and academic exchanges to be "closely connected" and improve the efficiency of creative behaviour.

\section{Conclusions}

Based on a grounded theory approach, this paper has provided new insights into the factors and 
structure of creativity in common spaces of universities. Five categories have been revealed: creative behaviour, characteristics in creative thinking, humanistic environment, physical space and individual potential. More specifically, creative behaviour is their core category; characteristics in creative thinking are internal factors; humanistic environment and physical space are external factors; and individual potential is the principal reason for differences in creative efficiency in universities.

In common spaces of universities, the humanistic environment has more of an influence than physical space. Different levels of creative individuals have different space requirements. Teachers prefer working in an independent and controllable small room, while students prefer working with others with similar backgrounds and identities.

A comfortable and controllable environment will help individuals improve their working efficiency. Creative thinking goes hand in hand with deep thinking and requires a gradual preheating process going from simple to deep; it must also maintain its continuity and in particular avoid sudden interruptions. Academic exchange functions as a guide to thinking; it can correct mistakes, arrange ideas and relieve mental tension. It is therefore important to combine the functions of information acquisition, meditation and academic exchange within a small group of common spaces. Meanwhile, factors such as controllability, sense of belonging, space quality, and functionality can affect worktime length and concentration degree.

According to the characteristics in creative thinking and creative behaviour, for improving the efficiency of creativity, it is necessary to build a mix-used space with high appeal on the campus instead of focusing on functional partition, so that creative behaviours such as resources acquisition, immersion thinking, and academic exchanges should be closely connected to improve the efficiency of creative behaviour.

\section{Further works}

This paper uses the grounded theory method to study the relationship between creativity and common spaces of universities, and give some conclusions. However, there are still many shortcomings in the current work. There are mainly the following aspects:

1) Limitations of the grounded theory

Although the grounded theory is applicable to this study, it has strict rules and procedures, which make the grounded theory is more suitable for dealing with multi-concept, multi-variable relationships than quantitative research. However, it also has some shortcomings. Due to the reliance on the researcher's experience and tacit knowledge, certain research biases may occur, such as the analyst's theoretical sensitivity (Strauss, 1987). At the same time, due to the limited amount of research data applied by grounded theory, it is not a substitute for quantitative empirical research on broader data. For further work, a large scale survey is needed based on hypotheses that are generated by this study.

2) Limitations of the research objects

This study has certain limitations in the selection of research subjects. The research objects in this paper are mainly selected from Chinese teachers and students in representative universities, so there is a lack of cross-cultural comparative research on users of different races and nationalities. Chinese research institutions have their own characteristics. Generally, Chinese universities have clear campus boundaries with solid walls and need to provide dormitories for all students on campus, which inevitably forms a large campus. However, in the huge campus, it is not easy to find a suitable space for people to sit and talk for long periods of time. For example, restaurants in Chinese universities are mostly large scale for more than 500 people, instead of small cafes. The noise in large restaurants makes people reluctant to communicate for a long time there ( $\mathrm{Su}, 2014)$.

At the same time, the teacher's office, it is often designed as the open-plan office for multi-person using, and even some offices are mixed with teachers and students. This mode of use makes teachers often complain that there is no independent and quiet office space on campus. These Chinese university space design and use characteristics make the research objects have certain limitations. 
3) Differences in teachers and students

Although this paper compares the data of teachers and students, users of different levels of creativity have great differences in environmental requirements. For example, students in different grades have different needs for the learning space, just as undergraduates prefer to group study and graduate students need more personal space. Teachers and students have more complex differences in age, experience, perception and expectation, so a deeper and more accurate study should be needed.

\section{Acknowledgments}

This work was jointly supported by National Natural Science Foundation of China (51508127), Natural Science Foundation of Heilongjiang Province (E2015012), Postdoctoral Foundation of Heilongjiang Province (LBH-Z14099), and Harbin institute of technology innovation foundation (HIT.NSRIF.201657). The authors are also indebted to the interviewees for their participation and patience. 


\section{References}

Amabile, T. M. (1988). A model of creativity and innovation in organizations. In B. S. Cummings (Ed.), Research in organizational behavior (pp. 123s are Greenwich: JAI Press.

Amabile, T. M., \& Pratt, M. G. (2016). The dynamic componential model of creativity and innovation in organizations: making progress, making meaning . Research in Organizational Behavior, 36.Arlow J, Brenner C. (1964). Psychoanalytic concepts and the structural theory. Memoirs of Tottori College 19(4):45-55

Baddeley, A. (1992). Working memory. Science,255(5044), 556.

Beck C.T. (1993). Qualitative research: the evaluation of its credibility, fittingness, and auditability. Western Journal of NursingResearch 15, 263-266.

Chen X. (2006). Qualitative research in social sciences. Beijing: Educational Science Publishing House.

CHESSICK RD. (2001). Psychoanalytic explorations in art. American Journal of Psychiatry 158(3):506507, doi:10.1176/appi.ajp.158.3.506.

Choi JN (2004). Individual and contextual predictors of creative performance: the mediating role of psychological processes. Creativity Research Journal 16(2-3):187-199, doi:10.1080/10400419.2004.9651452.

Csikszentmihalyi M. (1996). On runco's problem finding, problem solving, and creativity. Creativity Research Journal 9(2-3):267-268

Zhou, D., \& Shi, J. (2005). Creative Process: From the Information Processing Perspective. Advances in Psychological Science, 13(06), 721-727.

Dietrich A. (2004). The cognitive neuroscience of creativity. Psychonomic Bulletin \& Review 11(6):1011-1026, doi:10.3758/BF03196731.

Dijksterhuis A, Nordgren LF. (2006). A theory of unconscious thought. Perspectives on Psychological Science 1(2):95

DrazinR. Glynn, M. A. \& Kazanjian, R. K. (1999). Multilevel theorizing about creativity in organizations:a sensemaking perspective.Academy of Management Review,24(2), 286-307.

Ellis C, Strauss A, Corbin J. (1992). Basics of qualitative research: grounded theory procedures and techniques. Contemporary Sociology 21(1):138.

Gardner, H. Csikszentmihalyi, M. \& Damon, W. (2001). Good work: when excellence and ethics meet. Ethics.

Glaser B.G. (2008). Conceptualization: On theory and theorizing using grounded theory. International Journal of Qualitative Methods 1(2):23-38.

Glaser B.G. (1978). Theoretical sensativity: Advances in the methodology of grounded theory. Journal of Investigative Dermatology 2(5):368-377.

Glaser, B. G. (1992). Basics of Grounded Theory Analysis: Emergence vs. Forcing. Mill Valley, CA: Sociology Press

Gruber, H. E., \& Wallace, D. B. (1999). The case study method and evolving systems approach for understanding unique creative people at work. In Handbook of creativity (Vol. 93, pp. 93-115). New

York, US: Cambridge University Press

Guiller, J.Durndell, A. \& Ross, A. (2008). Peer interaction and critical thinking: face-to-face or online discussion?Learning \& Instruction, 18(2), 187-200.

Guba E. \& Lincoln Y. (1981). Effective Evaluation. Jossey-Bass, SanFrancisco, CA.

Guilford JP. (1950). Creativity. American Psychologist 5(9):444-454.

Harris G, Galton F (1870) Hereditary Genius, vol 1. London: Macmillan., ,

Katz, A. N. (1983). Creativity and individual differences in asymmetric cerebral hemispheric functioning. Empirical Studies of the Arts, 1(1), 3-16.

Knoblich G, Ohlsson S, Haider H, Rhenius D. (1999). Constraint relaxation and chunk decomposition in insight problem solving. Journal of Experimental Psychology: Learning, Memory, and Cognition 25(6):1534-1555.

Leydesdorff, L., \& Etzkowitz, H. (1996). Emergence of a triple helix of university-industrygovernment relations. Science \& Public Policy, 23(5), 279-286 
Lincoln, Y., \& Guba, E. (1985). Naturalistic inquiry. Beverly Hills, CA: Sage.

Lubart TI, Kurtzberg TR, Amabile TM (2010) Models of the creative process: Past, present and future. Creativity Research Journal 13(November 2014):295-308. doi:10.1207/S15326934CRJ1334.

Martindale C, Hasenfus N. (1978). EEG diff erences as a function of creativity, stage of the creative process and eff ort to be original. Biological Psychology 6(3):157-167. doi:10.1016/03010511(78)90018-2.

Martindale C, Hines D, Mitchell L, Covello E. (1984). EEG alpha asymmetry and creativity. Personality and Individual Diff erences 5(1):77-86,

Moneta GB, Csikszentmihalyi M. (1996). The eff ect of perceived challenges and skills on the quality of subjective experience. Journal of Personality 64(2):275-310. doi:10.1111/j.14676494.1996.tb00512.x.

Moultrie, J., Nilsson, M. Dissel, M., Haner, U. E., Janssen, S.\& Lugt, R. V. D. (2007). Innovation spaces: towards a framework for understanding the role of the physical environment in innovation. Creativity \& Innovation Management, 16(1), 53-65.

Myerson, J., \& Ross, P. (2006). Space to work: New office design. London: Laurence King.

Ng AK. (2003). A cultural model of creative and conforming behaviour. Creativity Research Journal 15(2-3):223-233, doi:10.1080/10400419.2003.9651414.

Nonaka I. (1991). The knowledge-creating company. Harvard Business Press, doi:10.1016/B9780-75067009-8.50016-1.

Patton, M. (1990). Qualitative evaluation and research methods. Newbury Park, CA: Sage.

Postle BR. (2003). Context in verbal short-term memory. Memory \& cognition 31(8):1198-1207, doi:10.3758/BF03195803

Ranga, M., \& Etzkowitz, H. (2010). Creative reconstruction: A triple helix-based innovation strategy in central and eastern Europe countries. Theory and Practice of Triple Helix Model in Developing ountries: Issues and Challenges. UK: Routledge, 249-282.

Ritter SM, van Baaren RB, Dijksterhuis A. (2012). Creativity: The role of unconscious processes in idea generation and idea selection. Thinking Skills and Creativity 7(1):21-27, doi:10.1016/j.tsc.2011.12.002

Runco, M. A., \& Albert, R. S. (2010). Creativity research: a historical view. In J. C. Kaufman, J. Caaa, \& R. J. Sternberg (Eds.). The cambridge handbook of creativity (pp.3-19). New York: Cambridge University Press.

Simonton DK. (2003). Scientific creativity as constrained stochastic behaviour: The integration of product, person, and process perspectives. Psychological Bulletin 129(4):475-494, doi:10.1037/00332909.129.4.475.

Sternberg RJ. (2006). Creating a vision of creativity: the first 25 years. Psychology of Aesthetics, Creativity and the Arts S(1):2-12, doi:10.1037/1931-3896.S.1.2.

Sternberg, R. J., \& Davidson, J. E. (1995). The nature of insight. Cambridge, MA, US: MIT Press.

Strauss, A. L. (1987). Qualitative analysis for social scientists. Cambridge University Press.

Su W. (2013). Sound environment and construction strategies in university campus base on knowledge innovation and mind-body growth research. PhD thesis, Harbin Institute of Technology.

Su, W. (2014). Soundscape feature and optimization of knowledge innovation environments in the university campus. New Architecture, 05, 44-47.

Wallas, G. (1926). The art of thought. J. Cape: London.

Ward T. (1994). Structured imagination: the role of category structure in exemplar generation. Cognitive Psychology 27(1):1-40.

Ward TB, Smith SM, Finke RA. (1992). Creative cognition. Handbook of Creativity. pp: 189- 212, doi:10.1017/CBO9780511807916.012

Wierzbicki AP, Nakamori Y. (2005). Creative space: models of creative processes for the knowledge civilization age. American School \& University 1(Summer):288, doi:10.1007/b137889

Woodman, R., Sawyer, J., \& Griffin, R. (1993). Toward a theory of organizational creativity.

Academy of Management Review, 18(02), 293-321.

WU JX, HUANG XT. (2013). Preliminary exploration on the structure of the concept of integrity. Acta 
Psychologica Sinica 44(3):354-368, doi:10.3724/SP.J.1041.2012.00354. 